\title{
Carbono orgânico e nitrogênio total nas frações granulométricas e húmicas em solos sob diferentes texturas
}

\author{
Gisele Cristina de CASTRO ${ }^{1}$, Cristiane Ramos VIEIRA ${ }^{2 *}$, Oscarlina Lúcia dos Santos WEBER ${ }^{3}$ \\ ${ }^{1}$ Secretaria de Ciência e Tecnologia do Estado de Mato Grosso, Diamantino, MT, Brasil. \\ ${ }^{2}$ Faculdade de Agronomia, Universidade de Cuiabá, Cuiabá, MT, Brasil. \\ ${ }^{3}$ Programa de Pós-Graduação em Agricultura Tropical, Universidade Federal de Mato Grosso, Cuiabá, MT, Brasil. \\ *E-mail: cris00986@hotmail.com
}

Recebido em julho/2017; Aceito em abril/2018.

\begin{abstract}
RESUMO: A decomposição e distribuição dos componentes da matéria orgânica são influenciados diretamente pela textura do solo e podem se dar de forma diferenciada ao longo do perfil de solo. Diante disso, desenvolveu-se experimento para avaliar o teor de carbono orgânico (CO) e de nitrogênio total (NT) nas frações granulométricas e húmicas de solos sob diferentes texturas. Foram coletadas amostras em cinco quadrantes, nas profundidades de 0-20, 20-40, 40-60 e 60-100 cm. Essas amostras foram secas e passadas em peneira de 2,0 $\mathrm{mm}$ para os fracionamentos físico e químico. $\mathrm{O}$ fracionamento físico foi realizado por meio de ultrasom e as frações húmicas através da extração alcalina. O teor de CO foi determinado pela digestão sulfocrômica a quente seguida de titulação com sulfato ferroso amoniacal, enquanto o teor de nitrogênio foi obtido pela digestão seguida de destilação e titulação. Os teores de CO foram maiores na fração $>53 \mu \mathrm{m}$ e os de NT na fração $<53 \mu \mathrm{m}$. A fração ácido húmico $(\mathrm{FAH})$ teve o maior teor de carbono e a fração humina (FHum) teve o menor teor. A relação extrato alcalino (EA/Hum) variou de 22,09 a 24,76 $\mathrm{g} \mathrm{Kg}^{-1}$ indicando predomínio da fração húmica na camada superficial.
\end{abstract}

Palavras-chave: fracionamento físico e químico, matéria orgânica, granulometria do solo.

\section{Organic carbon and total nitrogen in granulometric and humic fractions in soils under different textures}

\begin{abstract}
The decomposition and distribution of the organic matter components are directly influenced by the soil texture and can occur differently along the soil profile. Therefore, an experiment was developed to evaluate the organic carbon (OC) and total nitrogen (TN) content of the granulometric and humic fractions of soils under different textures. Samples were collected on five quadrants, at depths of 0-20, 20-40, 40-60 and 60$100 \mathrm{~cm}$. These samples were dried and passed through a $2.0 \mathrm{~mm}$ sieve to be submitted to the physical and chemical fractionations. The physical fractions were obtained by means of ultrasound and the humic fractions through the alkaline extraction. The OC content was determined by hot sulfocromic digestion followed by titration with ammoniacal ferrous sulfate, while the nitrogen content was obtained by digestion followed by distillation in semi-microdistiller and titration. The OC contents were higher in the fraction $>53 \mu \mathrm{m}$ and $\mathrm{TN}$ in the fraction $<53 \mu \mathrm{m}$. The humic acid fraction (HAF) had the highest carbon content and the humic fraction (HUMF) had the lowest content. The alkaline extract ratio (AE /HUM) ranged from 22.09 to $24.76 \mathrm{~g} \mathrm{Kg}^{-1}$ indicating predominance of the humic fraction in the surface layer.
\end{abstract}

Keywords: physical and chemical fractionation, organic matter, soil granulometry.

\section{INTRODUÇÃO}

O teor de matéria orgânica do solo (MOS) influencia nas propriedades físicas, químicas e biológicas do solo. Porém, também pode ser influenciada pelas características deste solo.

As taxas de decomposição da matéria orgânica (MO) podem variar de acordo com a textura do solo, contribuindo para o aumento ou redução da quantidade de carbono (C) e de nitrogênio $(\mathrm{N})$ ao longo do perfil.

De acordo com Reichardt; Timm (2012), isso acontece porque a textura é fator determinante das propriedades de retenção e capacidade de armazenamento de água e nutrientes, da distribuição de poros e, consequentemente, das propriedades de condução de água e gases. Solos com maiores teores de argila têm a propriedade de favorecer a formação de aglomerados de partículas unitárias, que se formam por causa de atrações físicas entre partículas ou através de agentes cimentantes, como óxidos de ferro e MO (FREITAS et al., 2013).

A textura do solo afeta a estabilidade e a própria formação de agregados, e solos com maior teor de argila favorecem a agregação (SILVA et al., 2014). Enquanto o elevado teor de areia afeta a formação de agregados estáveis (SANTOS et al., 2011). Portanto, em geral, quanto maiores as partículas do solo, menor sua compressibilidade e agregação (MACEDO et al., 2010).

Barros et al. (2016) ao estudar a distribuição da porosidade textural e estrutural em solos de Terra Preta Arqueológica na região Amazônica concluíram que, um melhor entendimento das propriedades físicas dos solos da região pode fornecer informações importantes para o manejo sustentável dos seus solos, visto que, apesar do seu uso contínuo, estes apresentam uma alta capacidade de 
resiliência. Portugal et al. (2010) estudando solos sob mata, seringueira e laranjeira verificaram que a estabilidade de agregados está relacionada aos maiores teores de carbono orgânico total (COT), nitrogênio total (NT), ácidos fúlvicos, ácidos húmicos, humina, carbono microbiano e matéria orgânica leve, enquanto na pastagem degradada está principalmente relacionada a ciclos de umedecimento e secagem. Ao estudar os estoques de $\mathrm{C}$ e $\mathrm{N}$ em frações lábeis e estáveis da MO, Pulrolnik et al. (2009) observaram que as frações da MOS que mais contribuíram para o estoque de $\mathrm{C}$ e $\mathrm{N}$ nos solos estudados foram a humina, o ácido húmico, o ácido fúlvico e a matéria orgânica leve. A biomassa microbiana do solo teve pouca contribuição para os estoques de $\mathrm{C}$ e $\mathrm{N}$ do solo.

Diante da importância que as frações texturais têm na decomposição e distribuição dos componentes da MO no solo, desenvolveu-se pesquisa para avaliar o teor de carbono orgânico (CO) e do nitrogênio total (NT) nas frações granulométricas e húmicas de solos sob diferentes texturas.

\section{MATERIAL E MÉTODOS}

\subsection{Caracterização da área de estudo}

A área de estudo está localizada na Fazenda São Nicolau, município de Cotriguaçu, região noroeste de Mato Grosso, cujas coordenadas são 58 19'38" N e 947'51" O. Segundo a classificação de Köppen (Brasil, 1982) o clima predominante na região é o tropical chuvoso do tipo $\mathrm{Am}$, com período de seca e chuvas inferiores a $60 \mathrm{~mm}$ no mês mais seco. As temperaturas médias anuais permanecem entre $23^{\circ}$ e $25^{\circ} \mathrm{C}$, sendo os meses da primavera-verão os mais quentes, que coincide com o período mais chuvoso e precipitação abundante, com curto período seco no inverno (SILVA et al., 2008).

Os solos predominantes na área de estudo são os Argissolos Vermelho-Amarelo distrófico e álico, com textura argilosa, ocorrendo ainda, em menores proporções, os Neossolos Litólicos em relevo mais movimentado e Gleissolos ao longo da rede de drenagem. A cobertura vegetal nativa na propriedade é a Floresta Ombrófila Aberta, formação submontana com palmeiras (BRASIL, 1982).

\subsection{Amostragem de solo}

A área do estudo foi dividida em cinco quadrantes, Q1, Q2, Q3, Q4 e Q5 (Figura 1), nos quais foram delimitados três pontos amostrais. A divisão da área em quadrantes foi realizada de acordo com a variação textural do solo em: média, argilosa, muito argilosa. Nesses pontos foram coletadas amostras de solos nas profundidades de 0-20, 2040, 40-60 e 60-100 cm para as determinações dos teores de C e de $\mathrm{N}$ nas frações granulométricas, utilizando $\mathrm{o}$ delineamento em blocos casualizados e três repetições.

Para o fracionamento das substâncias húmicas em ácidos fúlvicos, húmicos e humina, utilizaram-se amostras da camada de $0-20 \mathrm{~cm}$. As amostras foram secas em estufa de circulação forçada de ar a $50^{\circ} \mathrm{C}$ até peso constante, destorroadas e peneiradas em malha de $2 \mathrm{~mm}$ e, em seguida, foram submetidas às determinações dos teores de $\mathrm{C}$ e de $\mathrm{N}$ nas frações granulométricas e substâncias húmicas (SHs).

\subsection{Fracionamento físico granulométrico do solo}

O fracionamento físico da matéria orgânica do solo (MOS) foi realizado pelo método de Cambardella; Elliott (1992) e envolveu dois processos: a dispersão em meio aquoso a partir de $20 \mathrm{~g}$ de TFSA em ultrasom (240 Watts) durante seis minutos em temperatura controlada. Desse processo, a suspensão foi passada em peneira de malha de 53 $\mu \mathrm{m}$, obtendo-se a fração areia $(53>200 \mu \mathrm{m})$ e a fração silte/argila $(<53 \mu \mathrm{m})$, respectivamente.

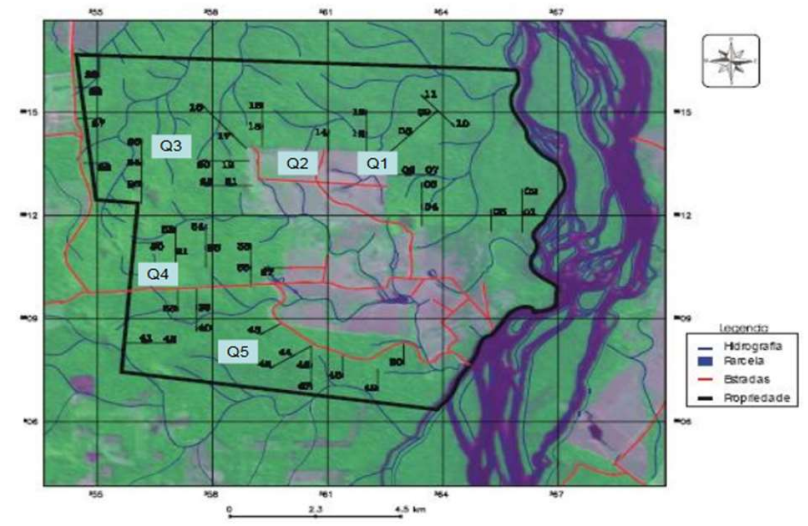

Figura 1. Localização das unidades amostrais. Fonte: Imagem CBERS-2(2005).

Figure 1. Localization of sample units. Source: Picture CBERS2(2005).

As frações granulométricas foram levadas a secar em estufa de ventilação forçada de ar à temperatura de $50^{\circ} \mathrm{C}$, até peso constante, para obtenção do percentual de cada fração em relação à massa total da amostra. As frações de cada repetição e de cada fração foram maceradas em graal, para posteriores determinações dos teores do $\mathrm{C}$ e de $\mathrm{N}$.

$\mathrm{O} \mathrm{CO}$ foi determinado pelo método descrito por Yeomans; Bremner (1988), que consistiu em digerir 0,5 $\mathrm{g}$ de TFSA, peneirado em malha de $0,297 \mathrm{~mm}$, em $5 \mathrm{~mL}$ de $\mathrm{K}_{2} \mathrm{Cr}_{2} \mathrm{O}_{7}$ 0,167 mol L-1 e 7,5 mL de $\mathrm{H}_{2} \mathrm{SO}_{4}$ concentrado, por 30 minutos a $170^{\circ} \mathrm{C}$, em bloco digestor. Após o resfriamento em temperatura ambiente, os extratos foram transferidos para erlenmeyers de $250 \mathrm{~mL}$, utilizando-se água destilada suficiente para um volume final de até $80 \mathrm{~mL}$. Em seguida, adicionou-se $0,3 \mathrm{~mL}$ de solução indicadora de ferroin em cada erlenmeyer, procedendo-se a titulação com solução de $\mathrm{Fe}\left(\mathrm{NH}_{4}\right)_{2}\left(\mathrm{SO}_{4}\right)_{2} \cdot 6 \mathrm{H}_{2} \mathrm{O} \quad 0,20 \mathrm{~mol} \mathrm{~L}^{-1}$ (sal de Mohr). Paralelamente, foram realizadas provas em branco, com e sem aquecimento. O teor de $\mathrm{CO}$ no solo nas frações foram obtidas pela equação 1 .

$$
\mathrm{CO}=\frac{\left[(\mathrm{Vba}-\mathrm{Vam}) * \frac{\mathrm{Vbn}-\mathrm{V}}{\mathrm{Vbn}}\right]+(\mathrm{Vba}-\mathrm{Vam}) *[\mathrm{M}] *(3) *(100)}{\mathrm{Ms}}
$$

em que: $\mathrm{CO}=$ carbono orgânico $\left(\mathrm{dag} \mathrm{kg}^{-1}\right) ; \mathrm{Vba}=$ volume gasto na titulação do branco aquecido; $\mathrm{Vbn}=$ volume gasto na titulação do branco sem aquecimento; Vam = volume gasto na titulação da amostra; $[\mathrm{M}]=$ molaridade do sulfato ferroso; $\mathrm{Ms}=$ massa da amostra de solo em miligrama.

Para a determinação do teor de NT, utilizou-se o método Kjedhal, que envolveu o uso de uma solução digestora à base de $\mathrm{Na}_{2} \mathrm{SO}_{4}, \mathrm{CuSO}_{4} .5 \mathrm{H}_{2} \mathrm{O}, \mathrm{Na}_{2} \mathrm{SeO}_{3}$ e $\mathrm{H}_{2} \mathrm{SO}_{4}$ concentrado. $\mathrm{O}$ teor de $\mathrm{N}$ no solo e nas frações foram obtidas pela equação 2 .

$$
\mathrm{N}=\frac{\text { Vam } * \mathrm{M}[\mathrm{HCl}] * 0,014 * 100}{\mathrm{Ms}}
$$

em que: $\mathrm{N}=$ nitrogênio $\left(\mathrm{em} \mathrm{dag} \mathrm{kg}^{-1}\right)$; Vam = volume gasto na titulação; $[\mathrm{HCl}]=$ concentração da solução de ácido clorídrico; $\mathrm{Ms}=$ massa da amostra de solo, em gramas. 


\subsection{Extração das substâncias húmicas do solo}

A extração das substâncias húmicas nas amostras de solos foi feita por meio do método de Kononova (1966), que consistiu em pesar $5 \mathrm{~g}$ de TFSA em tubo de centrífuga de 50 $\mathrm{mL}$ e adicionar $25 \mathrm{~mL}$ de $\mathrm{H}_{3} \mathrm{PO}_{4} 2 \mathrm{M}$. Em seguida, levou-se a agitar por 30 minutos em agitador orbital e a centrifugar a $3.000 \mathrm{rpm}$ por 10 minutos para obtenção da fração ácido fúlvico livre (AFL). Esta operação foi repetida mais duas vezes. Logo após, o precipitado foi lavado com $25 \mathrm{~mL}$ de água destilada e centrifugado a $3.000 \mathrm{rpm}$ por 10 minutos. $\mathrm{O}$ sobrenadante foi filtrado em papel filtro e descartado, procedimento que também foi repetido por três vezes. Os restos vegetais $(\mathrm{RV})$ retidos no papel filtro serviram para determinar o teor de matéria orgânica livre (MOL).

A extração da fração do ácido fúlvico mais ácido húmico (FAF+FAH) foi realizada por meio alcalino. Após as lavagens anteriores com água destilada, juntou-se ao precipitado retido ao tubo da centrífuga, $25 \mathrm{~mL}$ de solução de pirofosfato de sódio + hidróxido de sódio, agitou-se por 5 minutos em agitador horizontal e deixou-se a mistura em repouso por 12 horas. Após o repouso a mistura foi centrifugada a $3.000 \mathrm{rpm}$ por 10 minutos guardando o sobrenadante em frascos (essa operação foi repetida por três vezes), obtendo-se, dessa forma, a fração ácido fúlvico + fração ácido húmico (FAV+FAH) e o precipitado que foi a fração humina (HUM).

A separação do ácido húmico (AH) ocorreu em um tubo de centrífuga de $50 \mathrm{~mL}$ onde pipetou-se $25 \mathrm{~mL}$ da solução $\mathrm{FAV}+\mathrm{FAH}$ e adicionou-se $\mathrm{H}_{2} \mathrm{SO}_{4}$ concentrado até atingir $\mathrm{pH}$ $\pm 1,0$, deixando decantar em geladeira por 12 horas. O resultante foi centrifugado a $4.500 \mathrm{rpm}$ por 15 minutos descartando o sobrenadante, em seguida, redissolveu-se o precipitado com $25 \mathrm{~mL}$ de $\mathrm{NaOH} 0,1 \mathrm{M}$ para a obtenção da fração AH. Obtidas as separações procedeu-se às determinações do $\mathrm{CO}$ nas frações húmicas.

Para a determinação do $\mathrm{CO}$ das frações: Fração Ácido Fúlvico Livre (FAFL), Fração Ácido Fúlvico (FAF) e Fração Ácido Húmico (FAH), utilizou-se o método de Kononova (1966). Nesse caso, foram pipetados $5 \mathrm{~mL}$ do extrato para tubos de digestão de $100 \mathrm{~mL}$, adicionados $10 \mathrm{~mL}$ da solução $0,033 \mathrm{~K}_{2} \mathrm{Cr}_{2} \mathrm{O}_{7}$ com pipeta volumétrica e acrescentados 10 $\mathrm{mL}$ de $\mathrm{H}_{2} \mathrm{SO}_{4}$. Os tubos foram colocados no bloco digestor pré-aquecido a $170^{\circ} \mathrm{C}$ por 30 minutos. O conteúdo foi deixado para esfriar por 15 minutos e, em seguida, transferido para erlenmeyers de $250 \mathrm{~mL}$, completando com água destilada suficiente para atingir o volume final de 80 $\mathrm{mL}$. A solução foi deixada em repouso até a temperatura ambiente, adicionando-se, posteriormente, três gotas de difenilamina (solução indicadora). O conteúdo foi titulado com solução de sulfato ferroso amoniacal $0,03 \mathrm{~mol} \mathrm{~L}^{-1}$.

Para a determinação do CO na HUM, pesou-se $\pm 0,5 \mathrm{~g}$ do precipitado do fundo do tubo da centrífuga de $50 \mathrm{~mL}$, para tubos de digestão de $100 \mathrm{~mL}$, adicionou-se $5 \mathrm{~mL}$ da solução $0,167 \quad \mathrm{~mol}^{-1} \quad \mathrm{~K}_{2} \mathrm{Cr}_{2} \mathrm{O}_{7}$ e $7,5 \mathrm{~mL}$ de $\mathrm{H}_{2} \mathrm{SO}_{4}$. Os procedimentos seguintes foram semelhantes aos descritos para as frações húmicas anteriores com diferença na titulação em que se utilizou sulfato ferroso amoniacal $0,2 \mathrm{~mol} \mathrm{~L}^{-1}$.

Para as análises estatísticas dos dados, utilizou-se o programa computacional Sisvar com a aplicação da análise de variância e do teste de médias de Tukey a 5\% de probabilidade. Outro teste realizado foi o de correlação entre as variáveis estudadas.

\section{RESULTADOS}

As análises texturais em cada um dos locais (quadrantes) de coleta de solo e em suas respectivas profundidades estão apresentadas na Tabela 1. A massa de solo, os teores de $\mathrm{CO}$ e de NT na fração $>53 \mu \mathrm{m}$ estão apresentados na Tabela 2.

Tabela 1. Granulometria e grupamento textural dos solos estudados. Table 1. Granulometry and textural grouping of the studied soils.

\begin{tabular}{cccccc}
\hline Quadr./T & Prof. & Argila & Silte & Areia & Textura \\
\cline { 2 - 6 } ext. & $\mathrm{cm}$ & & $\mathrm{g} \mathrm{kg}^{-1}$ & & \\
\hline \multirow{2}{*}{ Q1 } & $0-20$ & 153 & 68 & 778 & Média \\
Média & $20-40$ & 225 & 85 & 690 & Média \\
& $60-60$ & 342 & 74 & 584 & Média \\
& $60-100$ & 470 & 52 & 478 & Argilosa \\
Q2 & $20-20$ & 284 & 14 & 702 & Média \\
Argilosa & $40-60$ & 406 & 30 & 564 & Argilosa \\
& $60-100$ & 589 & 23 & 405 & Argilosa \\
\hline \multirow{2}{*}{ Q3 } & $0-20$ & 361 & 20 & 619 & Argilosa \\
Muito & $20-40$ & 487 & 34 & 479 & Argilosa \\
Argilosa & $40-60$ & 611 & 33 & 356 & M. argilosa \\
& $60-100$ & 665 & 27 & 308 & M. argilosa \\
\hline & $0-20$ & 309 & 63 & 628 & Média \\
Q4 & $20-40$ & 413 & 76 & 511 & Argilosa \\
Argilosa & $40-60$ & 505 & 55 & 440 & Argilosa \\
& $60-100$ & 322 & 76 & 602 & Média \\
\hline \multirow{2}{*}{ Q5 } & $0-20$ & 368 & 153 & 479 & Argilosa \\
Argilosa & $20-40$ & 401 & 148 & 451 & Argilosa \\
& $60-60$ & 562 & 48 & 390 & Argilosa \\
\hline Q & $60-100$ & 606 & 59 & 335 & M. argilosa \\
\hline
\end{tabular}

Quadr. = quadrante; Text. = textura; Prof. = profundidade; M. argilosa $=$ muito argilosa.

Tabela 2. Percentagem de massa do solo, teores de CO, NT e C/N nas frações granulométricas de solos sob diferentes texturas, fração $>53 \mu \mathrm{m}$.

Table 2. Percentage of soil mass, CO, NT and $\mathrm{C} / \mathrm{N}$ contents in the granulometric fractions of soils under different textures, fraction $>$ $53 \mu \mathrm{m}$.

\begin{tabular}{|c|c|c|c|c|c|}
\hline \multicolumn{6}{|c|}{ Fração $>53 \mu \mathrm{m}$} \\
\hline \multirow{2}{*}{ Quadrante } & Prof. & Massa & $\mathrm{CO}$ & NT & $\mathrm{C} / \mathrm{N}$ \\
\hline & $\mathrm{cm}$ & $\%$ & & $\mathrm{~g} \mathrm{~kg}^{-1}$ & \\
\hline \multirow{4}{*}{1} & $0-20$ & 70,76 & 14,40 & 32,20 & 0,45 \\
\hline & $20-40$ & 65,33 & 17,53 & 39,55 & 0,44 \\
\hline & $40-60$ & 51,99 & 16,22 & 39,55 & 0,41 \\
\hline & $60-100$ & 40,46 & 17,42 & 31,15 & 0,56 \\
\hline Média do perfil & $0-100$ & 57,13 & 16,39 & 35,61 & 0,46 \\
\hline \multirow{4}{*}{2} & $0-20$ & 71,35 & 21,02 & 32,90 & 0,64 \\
\hline & $20-40$ & 60,93 & 17,26 & 60,55 & 0,29 \\
\hline & $40-60$ & 47,36 & 16,38 & 23,45 & 0,70 \\
\hline & $60-100$ & 43,60 & 15,80 & 40,25 & 0,39 \\
\hline Média do perfil & $0-100$ & 55,81 & 17,62 & 39,29 & 0,50 \\
\hline \multirow[t]{4}{*}{ 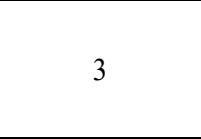 } & $0-20$ & 64,11 & 18,87 & 42,35 & 0,45 \\
\hline & $20-40$ & 50,88 & 17,31 & 45,85 & 0,38 \\
\hline & $40-60$ & 43,10 & 16,03 & 61,25 & 0,26 \\
\hline & $60-100$ & 40,99 & 21,04 & 32,20 & 0,65 \\
\hline Média do perfil & $0-100$ & 49,77 & 18,31 & 45,11 & 0,43 \\
\hline \multirow[t]{4}{*}{ 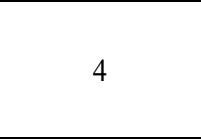 } & $0-20$ & 69,73 & 11,59 & 24,50 & 0,47 \\
\hline & $20-40$ & 65,76 & 21,84 & 39,20 & 0,56 \\
\hline & $40-60$ & 61,14 & 19,78 & 20,65 & 0,96 \\
\hline & $60-100$ & 57,63 & 17,86 & 47,95 & 0,37 \\
\hline Média do perfil & $0-100$ & 63,56 & 17,77 & 33,08 & 0,59 \\
\hline \multirow{4}{*}{ (2) } & $0-20$ & 69,21 & 22,12 & 35,70 & 0,62 \\
\hline & $20-40$ & 58,80 & 17,54 & 29,75 & 0,59 \\
\hline & $40-60$ & 44,50 & 15,48 & 47,25 & 0,33 \\
\hline & $60-100$ & 37,49 & 17,54 & 37,10 & 0,47 \\
\hline Média do perfil & $0-100$ & 52,50 & 18,17 & 37,45 & 0,50 \\
\hline
\end{tabular}

Prof. = profundidade. 
A massa de solo, os teores de CO e de NT na fração $<53$ $\mu \mathrm{m}$ estão apresentados na Tabela 3. Os teores de CO na fração resíduo vegetal, em relação aos quadrantes analisados estão apresentados na Figura 2. Os teores de CO nas frações húmicas estão na Figura 3.

Tabela 3. Percentagem de massa do solo, teores de CO, NT e C/N nas frações granulométricas de solos sob diferentes texturas, fração $<53 \mu \mathrm{m}$.

Table 3. Percentage of soil mass, $\mathrm{CO}, \mathrm{NT}$ and $\mathrm{C} / \mathrm{N}$ contents in the granulometric fractions of soils under different textures, fraction 53 $\mu \mathrm{m}$.

\begin{tabular}{|c|c|c|c|c|c|}
\hline \multicolumn{6}{|c|}{ Fração $<53 \mu \mathrm{m}$} \\
\hline \multirow{2}{*}{ Quadrante } & Prof. & Massa & $\mathrm{CO}$ & NT & $\mathrm{C} / \mathrm{N}$ \\
\hline & $\mathrm{cm}$ & $\%$ & \multicolumn{3}{|c|}{$\mathrm{g} \mathrm{kg}^{-1}$} \\
\hline \multirow{4}{*}{1} & $0-20$ & 27,88 & 20,56 & 2,80 & 7,34 \\
\hline & $20-40$ & 34,45 & 20,56 & 3,15 & 6,53 \\
\hline & $40-60$ & 48,50 & 20,49 & 3,15 & 6,51 \\
\hline & $60-100$ & 57,01 & 20,49 & 2,80 & 7,32 \\
\hline Média do perfil & $0-100$ & 41,96 & 20,52 & 2,98 & 6,92 \\
\hline \multirow{4}{*}{2} & $0-20$ & 26,40 & 23,80 & 3,15 & 7,56 \\
\hline & $20-40$ & 38,39 & 23,80 & 2,80 & 8,50 \\
\hline & $40-60$ & 51,38 & 18,84 & 3,15 & 5,98 \\
\hline & $60-100$ & 55,50 & 18,84 & 3,50 & 5,38 \\
\hline Média do perfil & $0-100$ & 42,92 & 21,32 & 3,15 & 6,85 \\
\hline \multirow{4}{*}{ 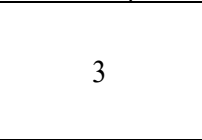 } & $0-20$ & 34,06 & 25,65 & 3,85 & 6,66 \\
\hline & $20-40$ & 47,90 & 25,65 & 2,80 & 9,16 \\
\hline & $40-60$ & 55,64 & 20,87 & 3,15 & 6,63 \\
\hline & $60-100$ & 60,09 & 20,87 & 3,50 & 5,96 \\
\hline Média do perfil & $0-100$ & 49,42 & 23,26 & 3,33 & 7,10 \\
\hline \multirow{4}{*}{ 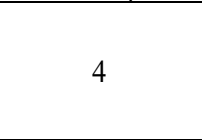 } & $0-20$ & 29,95 & 27,62 & 3,50 & 7,89 \\
\hline & $20-40$ & 31,98 & 27,62 & 3,50 & 7,89 \\
\hline & $40-60$ & 36,05 & 22,15 & 3,15 & 7,03 \\
\hline & $60-100$ & 39,29 & 22,15 & 3,15 & 7,03 \\
\hline Média do perfil & $0-100$ & 34,32 & 24,88 & 3,33 & 7,46 \\
\hline \multirow[t]{4}{*}{ 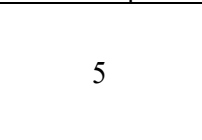 } & $0-20$ & 27,04 & 24,76 & 3,85 & 6,43 \\
\hline & $20-40$ & 37,34 & 24,76 & 2,45 & 10,10 \\
\hline & $40-60$ & 51,73 & 21,57 & 3,15 & 6,85 \\
\hline & $60-100$ & 61,39 & 21,57 & 3,15 & 6,85 \\
\hline Média do perfil & $0-100$ & 44,37 & 23,16 & 3,15 & 7,56 \\
\hline
\end{tabular}

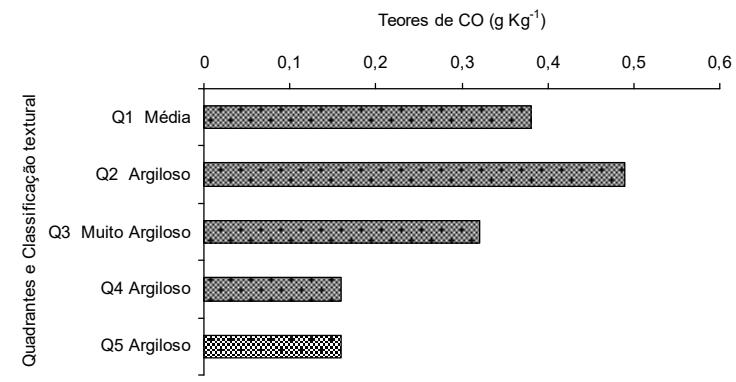

Figura 2. Teor de CO na fração resíduo vegetal.

Figure 2. $\mathrm{CO}$ content in the vegetal residue fraction.

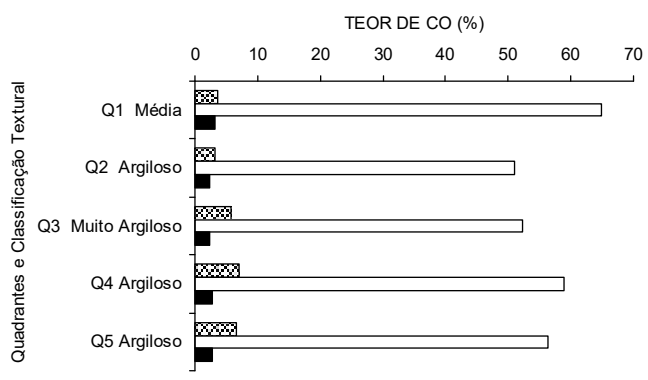

Figura 3. Teor de CO nas frações húmicas.

Figure 3. CO content in humic fractions.
A Figura 4 apresenta os dados para as frações húmicas em relação ao COT.

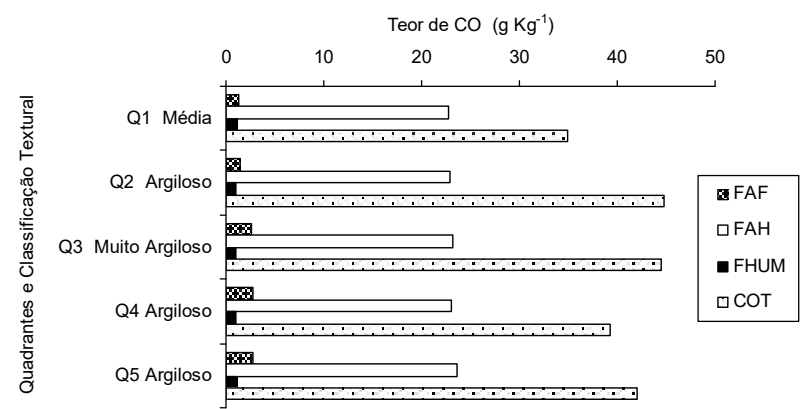

Figura 4. Relações entre as frações húmicas e COT $\left(\mathrm{g} \mathrm{kg}^{-1}\right)$.

Figure 4. Relationship between humic fractions and TOC $\left(\mathrm{g} \mathrm{kg}^{-1}\right)$.

Os teores de $\mathrm{CO}$ nas relações $\mathrm{AH} / \mathrm{AF}$ e EA/HUM podem ser observados na Figura 5.

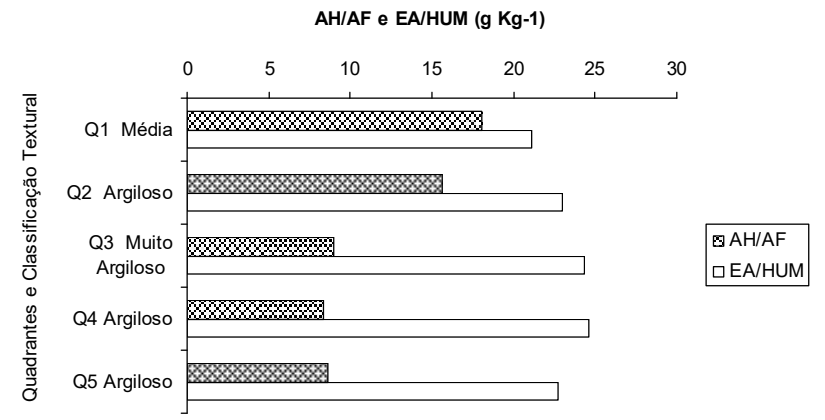

Figura 5. Teor de $\mathrm{CO}$ na relação AH/AF e EA/HUM.

Figure 5. CO content in $\mathrm{AH} / \mathrm{AF}$ and $\mathrm{EA} / \mathrm{HUM}$ ratio.

\section{DISCUSSÃO}

Nos quadrantes 1, 2, 3 e 5, o teor de argila aumentou da profundidade de $0-20 \mathrm{~cm}$ até $60-100 \mathrm{~cm}$ (Tabela 1). Apesar da maior deposição de material orgânico na camada de 0-20 $\mathrm{cm}$, esta apresentou, em geral, maior teor de areia dentre as demais camadas analisadas, independentemente do local de coleta, demonstrando que ocorreu translocação de material coloidal para camadas mais profundas.

No quadrante 4 (Tabela 1), o teor de argila aumentou nas profundidades de $20-40 \mathrm{~cm}$ e de $40-60 \mathrm{~cm}$, porém, voltou a reduzir na profundidade de $60-100 \mathrm{~cm}$. A maior quantidade de areia presente na camada superficial de $0-20 \mathrm{~cm}$ pode ter permitido a translocação da argila para camadas mais profundas, sem atingir, no entanto, a camada de $60-100 \mathrm{~cm}$ de forma significativa para ter sua textura alterada

Em geral, o quadrante 1 apresentou textura média; os quadrantes 2, 4 e 5 textura argilosa; e o quadrante 3 textura muito argilosa, de acordo com Embrapa (1999). Segundo Wendling et al. (2005) a predominância da fração argila pode estar relacionada à forte interação dessas frações com a matéria orgânica humificada, o que contribui para a estruturação do solo pela formação de agregados. Além disso, pode ocorrer maior perda do material orgânico das partículas da fração areia, que se deve à maior instabilidade, à suscetibilidade à oxidação e à desintegração dos resíduos vegetais e hifas de fungos presentes nessa fração, a qual se intensifica quando da adoção de cultivo (NEVES et al., 2004).

A massa de solo foi reduzida com a profundidade nos cinco quadrantes analisados quando avaliada na fração $>53$ 
$\mu \mathrm{m}$ (Tabela 2), cuja média foi maior no quadrante 4 com $63,56 \%$.

$\mathrm{Na}$ fração menor que $53 \mu \mathrm{m}$ (Tabela 3 ) houve aumento da percentagem de massa com a profundidade em todos os quadrantes analisados. Porém, com média superior no quadrante 3 .

Os teores de $\mathrm{CO}$ foram maiores na fração $<53 \mu \mathrm{m}$ (Tabela 3) em todos os quadrantes analisados quando comparados com a fração $>53 \mu \mathrm{m}$ (Tabela 2). Segundo Wendling et al. (2005) a predominância da MO na fração argila pode estar relacionada à forte interação dessas frações com a MO humificada, o que contribui para a estruturação do solo pela formação de agregados. Isso contribuiu para manter o maior teor de CO nas frações mais finas do solo.

$\mathrm{Na}$ fração $<53 \mu \mathrm{m}$ (Tabela 3) houve redução nos teores de $\mathrm{CO}$ com a profundidade nos cinco quadrantes analisados e a menor média foi observada no quadrante 4, portanto, assim, solos argilosos apresentaram menores taxas de decomposição da $\mathrm{MO}$ e consequentemente maior estabilidade química.

$\mathrm{Na}$ fração $>53 \mu \mathrm{m}$ (Tabela 2 ) houve aumento no teor de CO da profundidade de $0-20 \mathrm{~cm}$ para a camada mais profunda nos quadrantes 1 e 4 . O que pode ser explicado pelo fato do sistema radicular das espécies florestais nativas atingirem camadas mais profundas, com a morte dessas raízes em profundidade, a sua decomposição libera nutrientes nessas camadas.

De acordo com Denardin et al. (2014) outra explicação é o fato da degradação da MO ser maior em superfície, influenciando nos teores de carbono, ficando evidente que as maiores perdas de carbono ocorrem nas camadas superficiais devido a maior presença de microrganismos. Isso pode ter ocorrido devido à presença de $\mathrm{MO}$ e as condições de decomposição nessas camadas, que pode ter possibilitado a translocação de material orgânico para as camadas mais profundas.

No quadrante 2 o teor de $\mathrm{CO}$ reduziu com a profundidade e, nos quadrantes 3 e 5 houve redução até a profundidade de $40-60 \mathrm{~cm}$ com posterior aumento em $60-100 \mathrm{~cm}$. Em geral, os teores de $\mathrm{CO}$ foram maiores no quadrante 3 . Resultados que demonstram que a maior quantidade de material orgânico fica na superfície do solo, aumentando o acúmulo de MO em superfície. Consequentemente, o teor de CO presente também pode ser maior em relação às camadas mais subsuperficiais.

Os maiores teores de NT foram observados na fração $>$ $53 \mu \mathrm{m}$ (Tabela 2), nesse caso, houve aumento no teor da profundidade de $0-20 \mathrm{~cm}$ a $40-60 \mathrm{~cm}$ nos quadrantes 1 e 3 . Nos quadrantes 2 e 4 o aumento também ocorreu, porém, nas profundidades de $20-40$ e de $60-100 \mathrm{~cm}$.

Os teores encontrados nesta fração indicam que a maior parte do $\mathrm{N}$ está ligada a compostos orgânicos. Os teores de NT dos quadrantes analisados estão relativamente homogêneos indicando que, essas áreas têm acúmulos semelhantes desse elemento.

No quadrante 5 houve redução no teor de NT da profundidade de $0-20 \mathrm{~cm}$ para a de $20-40 \mathrm{~cm}$, com posterior aumento na de 40-60 cm e, queda na de $60-100 \mathrm{~cm}$.

A maior média para o teor de NT na fração $>53 \mu \mathrm{m}$ (Tabela 2) foi observada no quadrante 3, como ocorreu para os teores de $\mathrm{CO}$.

$\mathrm{Na}$ fração $<53 \mu \mathrm{m}$ (Tabela 3 ) houve aumento no teor de NT nas profundidades de $20-40 \mathrm{~cm}$ e de $40-60 \mathrm{~cm}$ no quadrante 1 . Nos quadrantes 2,3 e 5 observou-se redução da profundidade de $0-20 \mathrm{~cm}$ para a de $20-40 \mathrm{~cm}$ e posterior aumento para as demais profundidades. No quadrante 4 houve redução da profundidade de $20-40 \mathrm{~cm}$ para $60-100 \mathrm{~cm}$. Sendo que, esses teores foram maiores nos quadrantes 3 e 4 , coerente com o observado para os teores de CO.

A relação $\mathrm{C} / \mathrm{N}$ foi menor na fração $>53 \mu \mathrm{m}$ (Tabela 2) devido ao maior teor de NT em comparação com a fração < $53 \mu \mathrm{m}$ (Tabela 3). Algumas áreas podem apresentar maior relação $\mathrm{C} / \mathrm{N}$ devido à sua maior acumulação de COT e de $\mathrm{N}$ no perfil do solo, em razão da estabilidade das frações húmicas e menor grau de mineralização da MOS (CAMPOS et al., 2013). A maior relação $\mathrm{C} / \mathrm{N}$ acarreta degradação mais lenta e favorece o acúmulo de COT e $\mathrm{N}$ nos agregados do solo (LOSS et al., 2011). A maior relação $\mathrm{C} / \mathrm{N}$ na fração $>$ $53 \mu \mathrm{m}$ foi observada no quadrante 4 , com média de 0,59 . Nesse caso, houve aumento na relação $\mathrm{C} / \mathrm{N}$ até a profundidade de $40-60 \mathrm{~cm}$ e redução na de $60-100 \mathrm{~cm}$.

Nos quadrantes 1, 3 e 5 (Tabela 2) houve redução na relação $\mathrm{C} / \mathrm{N}$ da profundidade $0-20 \mathrm{~cm}$ até $40-60 \mathrm{~cm}$ e, posterior aumento devido aos teores de $\mathrm{CO}$ e de NT nessas profundidades. Nesse caso, a qualidade dos resíduos influenciou a incorporação da $\mathrm{MO}$, indicando menor transformação de $\mathrm{N}$ orgânico para $\mathrm{N}$ mineral. Além disso, houve favorecimento para perda de $\mathrm{N}$ em forma de gases. $\mathrm{O}$ que pode ter ocorrido no presente caso.

No quadrante 2 (Tabela 2) houve redução na profundidade de $20-40 \mathrm{~cm}$, aumento na de $40-60 \mathrm{~cm}$ e posterior redução na de $60-100 \mathrm{~cm}$ devido às variações nos teores de $\mathrm{CO}$ e de NT nessas camadas.

Para a relação $\mathrm{C} / \mathrm{N}$ na fração $<53 \mu \mathrm{m}$ (Tabela 3) observou-se as maiores médias em comparação com a fração $>53 \mu \mathrm{m}$ (Tabela 3), por causa dos teores de NT que foram menores e, consequentemente, do maior teor de CO. Nesse caso, as maiores médias foram verificadas nos quadrantes 4 $(7,46)$ e $5(7,56)$

No quadrante 1 (Tabela 3 ) houve redução até a profundidade de 40-60 $\mathrm{cm}$ e posterior aumento. Enquanto no quadrante 2 houve aumento na profundidade de $20-40 \mathrm{~cm}$ e posterior redução.

Os teores de CO na fração resíduo vegetal, em relação aos quadrantes analisados estão apresentados na Figura 2 e foi maior no quadrante 2, cujo solo foi classificado como argiloso. Esse resultado, provavelmente, está relacionado com o tipo de vegetação presente no local. Raij (2011) afirma que normalmente, quanto maior o teor de argila do solo mais alto é o teor de MO.

De acordo com Rangel; Silva (2007), nos sistemas florestais, as fontes de substâncias orgânicas estão associadas à deposição natural de resíduos de plantas, que alcançam o solo na forma de folhas, galhos e outros fragmentos orgânicos, bem como de substâncias orgânicas derivadas da decomposição das raízes. O que contribuiu para os resultados observados para os teores de COT e de NT ao longo do perfil do solo.

Com relação ao teor de $\mathrm{CO}$ nas frações húmicas (Figura 3) verificou-se que a maior fração foi a de ácido húmico (FAH), destacando-se no quadrante 1, que também apresentou a maior fração de humina (FHUM). Enquanto o quadrante 4 apresentou a maior fração de ácido fúlvico (FAF). Estudando a composição das substâncias húmicas em solos da Amazônia, Cunha et al. (2007) também verificaram 
predominância de FAH e atribuíram os resultados à formação de complexos MO-cálcio de alta estabilidade.

O somatório das frações húmicas representou, em média, $65 \%$ do COT, estabelecendo correlação linear positiva $(\mathrm{r}=$ 0,99). Os teores de C na FHum (Figura 4) foram menores que as demais frações, variando de 1,05 a $1,16 \mathrm{~g} \mathrm{~kg}^{-1}$, não tendo diferença entre os quadrantes. Este fato pode ocorrer devido à textura média na camada superficial, que provavelmente retarda a formação da humina.

De acordo com Fontana et al. (2010) em solos sob floresta, os ácidos húmicos são mais atuantes na agregação do que a fração humina.

A relação $\mathrm{AH} / \mathrm{AF}$ (ácido húmico/ácido fúlvico) nos quadrantes variou entre 8,37 e 18,02. Santos et al. (2013) observaram valores para a relação $\mathrm{AH} / \mathrm{AF}$ entre 0,02 e 6,55, com redução em profundidade, provavelmente, devido à perda da fração de ácido fúlvico.

A relação EA/HUM (extrato alcalino/humina) variou de 22,09 a 24,76 $\mathrm{g} \mathrm{kg}^{-1}$ indicando predomínio do extrato alcalino-solúveis. Este fato pode ter sido causado pelo grande volume de restos vegetais na camada superficial. Nesta camada, devido ao elevado teor de fibras, há predomínio de MO pouco decomposta na FHum, tendo relação maior que 1, indicando predomínio de compostos orgânicos alcalinosolúveis (VALLADARES et al., 2008).

A FAH constituiu-se de 26 a $59 \%$ do COT em todos os quadrantes, o que pode estar relacionado à interação da sua estrutura com a fração mineral do solo. Por outro lado, a FAF apresentou menor estabilidade, e a FHum evidenciou processos de movimentação no perfil, polimerização, ou mineralização, que diminuiu sua composição percentual no solo.

\section{CONCLUSÕES}

A fração textural predominante dentre os quadrantes estudados foi argila, cujos teores aumentaram com a profundidade, devido a translocação de material coloidal.

Os teores de CO foram maiores na fração mais fina do solo devido a sua maior capacidade de retenção, o que foi observado, principalmente, na fração ácido húmico e contribuiu para a maior relação $\mathrm{C} / \mathrm{N}$.

Os teores de NT foram maiores na fração mais grosseira, provavelmente, devido à maior percentagem de massa de solo e, consequentemente de MO.

A maior relação apresentada foi entre EA/Hum com valores acima de 20 , indicando predomínio de $\mathrm{MO}$ em estado de baixa decomposição, comum em ambientes nativos.

\section{REFERÊNCIAS}

BARROS, K. R. M.; LIMA, H. V.; RODRIGUES, S.; KERN, D. C. Distribuição da porosidade textural e estrutural em solos de Terra Preta Arqueológica. Revista Ciência Agronômica, Fortaleza, v. 47, n. 4, p. 609-615, out./dez. 2016. DOI: http://dx.doi.org/10.5935/18066690.20160073

BRASIL_Ministério das Minas e Energia. Departamento de Produção Mineral. Projeto RADAMBRASIL. Levantamento de Recursos Naturais Volume 20 - Folha SC 21 - Juruena. 1982.

CAMBARDElla, C. A.; ElliOT, E. T. Particulate soil organic-matter changes across a grassland cultivation sequence. Soil Science Society of America Journal, Madison, v. 56, n. 3, p. 777-783, mar. 1992. DOI: https://dx.doi.org/10.2136/sssaj1992.0361599500560003 $0017 \mathrm{x}$

CAMPOS, L. P.; LEITE, L. F. C.; MACIEL, G. A.; BRASIL, E. L.; IWATA, B. F. Estoque e frações de carbono orgânico em Latossolo Amarelo submetido a diferentes sistemas de manejo. Pesquisa Agropecuária Brasileira, Brasília, v. 48, n. 3, p. 304-312, mar. 2013. DOI: http://dx.doi.org/10.1590/S0100204X2013000300009

CUNHA, T. J. F.; MADRI, B. E.; BENITE V. M.; CANELLAS, L. P.; NOVOTNY, E. H.; MOUTTA, R. O.; TROMPOWSKY, P. M.; SANTOS, G. A. Fracionamento químico da matéria orgânica $\mathrm{e}$ características de ácidos húmicos de solos com horizonte a antrópico da Amazônia (Terra Preta). Acta Amazônica, Manaus, v. 37, n. 1, p. 91-98, 2007. DOI: http://dx.doi.org/10.1590/S0044-59672007000100010

DENARDIN, R. B. N.; MATTIAS,J. L.; WILDNER, L. P.; NESI, C. N.; SORDI, A.; KOLLING, D. F.; BUSNELLO, F. J.; CERUTTI, T. Estoque de carbono no solo sob diferentes formações florestais, Chapecó - SC. Ciência Florestal, Santa Maria, v. 24, n. 1, p. 59-69, jan./mar. 2014.

DOI: http://dx.doi.org/10.5902/1980509813323

EMBRAPA EMPRESA BRASILEIRA DE PESQUISA AGROPECUÁRIA. Sistema Brasileiro de Classificação de Solos. Rio de Janeiro: Embrapa Solos, 1999. 412 p.

FONTANA, A.; BRITO, R. J.; PEREIRA, M. G.; LOSS, A. Índices de agregação e a relação com as substâncias húmicas em Latossolos e Argissolos de tabuleiros costeiros, Campos dos Goytacazes, RJ. Revista Brasileira de Ciências Agrárias, Recife, v. 5, n. 3, p. 291-297, jul./set. 2010. http://dx.doi.org/10.5039/agraria.v5i3a461

FREITAS, L.; CASAGRANDE, J. C.; OLIVEIRA, I. A.; MORETI, T. C. F.; CARMO, D. A. B. Avaliação de atributos químicos e físicos de solos com diferentes texturas cultivados com cana-de-açúcar. Enciclopédia Biosfera, Jandaia, v. 9, n. 17, p. 362-374, 2013.

KONONOVA, M. M. Soil organic matter. Oxford: Pergamon Press, 1966. 272 p.

LOSS, A.; MORAES, A. G. L.; PEREIRA, M. G.; SILVA, E. M. R.; ANJOS, L. H. C. Carbono, matéria orgânica leve e frações oxidáveis do carbono orgânico sob diferentes sistemas de produção orgânica. Comunicata Scientiae, Bom Jesus, v. 1, n. 1, p. 57-64, 2010.

MACEDO V. R. M; SILVA A. J. N.; CABEDA M. S. V. Influência de tensões compressivas na pressão de précompactação e no índice de compressão do solo. Revista Brasileira de Engenharia Agrícola e Ambiental, Campina Grande, v. 14, n. 8, p. 856-862, ago. 2010. DOI: http://dx.doi.org/10.1590/S1415-43662010000800010

NEVES, C. M. N.; SILVA, M. L. N.; CURI, N.; MACEDO, R. L. G.; TOKURA, A. M. Estoque de carbono em sistema agrossilvopastoril, pastagem e eucalipto sob cultivo convencional na região noroeste de Minas Gerais. Ciência Agrotécnica, Lavras, v. 28, n. 5, p. 1038-1046, set./out. 2004. DOI: http://dx.doi.org/10.1590/S141370542004000500010

PORTUGAL, A. F.; JUNCKSH, I.; SCHAEFER, C. E. R. G.; NEVES, J. C. L. Estabilidade de agregados em Argissolo sob diferentes usos, comparado com mata. Revista Ceres, Viçosa, v. 57, n. 4, p. 545-553, jul./ago. 
2010 DOI: $\quad$ http://dx.doi.org/10.1590/S0034737X2010000400018

PULROLNIK, K.; BARROS, N.F.; SILVA, I.R.; NOVAIS, R.F.; BRANDANI, C.B. Estoques de carbono e nitrogênio em frações lábeis e estáveis da matéria orgânica de solos sob eucalipto, pastagem e cerrado no Vale do Jequitinhonha - MG. Revista Brasileira de Ciência do Solo, Viçosa, v. 33, n. 5, p. 1125-1136, jul./ago. 2009. DOI: http://dx.doi.org/10.1590/S010006832009000500006

RAIJ, B. VAN. Fertilidade do solo e manejo de nutrientes Piracicaba: International Plant Nutrition Institute, 2011. 420p.

RANGEL, O. J. P.; SILVA, C. A. Estoques de carbono e nitrogênio e frações orgânicas de Latossolo submetido a diferentes sistemas de uso e manejo. Revista Brasileira de Ciência do Solo, Viçosa, v. 31, n. 6, p. 1609-1623, nov./dez. 2007. DOI: http://dx.doi.org/10.1590/S010006832007000600037

REICHARDT, R.; TIMM, L. C. Solo Planta Atmosfera: conceitos, processos e aplicações. Barueri: Manole, 2012. $524 \mathrm{p}$.

SANTOS, D. C.; PILLON, C. N.; FLORES, C. A.; LIMA, C. L. R.; CARDOSO, E. M. C.; PEREIRA, B. F.; MANGRICH, A. S. Agregação e frações físicas da matéria orgânica de um Argissolo vermelho sob sistemas de uso no bioma Pampa. Revista Brasileira de Ciência do Solo, Viçosa, v. 35, n. 5, p. 1735-1744, set./out. 2011. DOI: http://dx.doi.org/10.1590/S010006832011000500028

SANTOS, L. L.; LACERDA, J. J. J.; ZINN, Y. L. Partição de substâncias húmicas em solos brasileiros. Revista Brasileira de Ciência do Solo, Viçosa, v. 37, n. 4, p.
955-968, jul./ago. $2013 . \quad$ DOI: http://dx.doi.org/10.1590/S0100-06832013000400013

SILVA, V. S. M.; TRAVAGIN, D.P.; COLPINI, C. Avaliação das potencialidades florestais e destinação de uso. Cuiabá: Universidade Federal de Mato Grosso, 2008. 60 p. (Comunicado técnico)

SILVA, A. S.; SILVA, I. F.; BANDEIRA, L. B.; DIAS, B. O.; SILVA NETO, L. F. Argila e matéria orgânica e seus efeitos na agregação em diferentes usos do solo. Ciência Rural, Santa Maria, v. 44, n. 10, p. 1783-1789, out. 2014. DOI: http://dx.doi.org/10.1590/0103-8478cr20130789

VALLADARES, G. S.; GOMES, E. G.; MELLO, J. C. C. B. S.; PEREIRA, M. G.; ANJOS, L. H. C.; EBELING, A. G.; BENITES, V. M. Análise dos componentes principais e métodos multicritério ordinais no estudo de organossolos e solos afins. Revista Brasileira de Ciência do Solo, Viçosa, v. 32, n. 1, p. 285-296, jan./fev. 2008. DOI: http://dx.doi.org/10.1590/S010006832008000100027

WENDLING, B.; JUCKSCH, I.; MENDONÇA, E. S.; NEVES, J. C. L. Carbono orgânico e estabilidade de agregados de um Latossolo Vermelho sob diferentes manejos. Pesquisa Agropecuária Brasileira, Brasília, v. 40, n. 5, p. 487-494, maio 2005. DOI: http://dx.doi.org/10.1590/S0100-204X2005000500010

YEOMANS, J. O.; BREMMER, J. M. A rapid and precise method for routine determination of organic carbon in soil. Journal Communications in Soil Science and Plant Analysis, New York, v. 19, n. 13, p. 1467-1476, nov. 1988.

DOI: https://dx.doi.org/10.1080/00103628809368027 